\title{
Correlates of prone infant sleeping position by period of birth
}

\author{
Anne-Louise Ponsonby, Terence Dwyer, Stanislav V Kasl, David Couper, \\ Jennifer A Cochrane
}

\begin{abstract}
Intervention to avoid the prone sleeping position during infancy has occurred in various countries after evidence that it increases the risk of sudden infant death syndrome (SIDS). This study examined cohort data to determine if correlates of the prone position differed by period of birth, before intervention (1 May 1988 to 30 April 1991) compared with after intervention (1 May 1991 to 30 April 1992). The usual prone sleeping position was more closely associated with the following factors after intervention: teenage motherhood, low maternal education, paternal unemployment, unmarried motherhood, non-specialist antenatal care, not reading books to prepare for a baby, poor smoking hygiene, and bottle feeding. For example, the association of usual prone position with being unmarried shown by the odds ratio (95\% confidence interval) was $0.54(0.47$ to 0.63 ) in the period before intervention and $1.92(1.18$ to 3.15$)$ in the period after intervention.

The alteration in correlates of the prone position reported here provide an example to support the theoretical concept that well known 'modifiable' risk factors for disease tend to be associated with each other in both populations and individuals. This phenomenon was not evident in the population before intervention, that is, before the prone sleeping position became a well known SIDS risk factor.

(Arch Dis Child 1995; 72: 204-208)
\end{abstract}

Keywords: prone position, sudden infant death, risk factor epidemiology, cohort.

Menzies Centre for Population Health Research, 17 Liverpool Street, Hobart, Tasmania, Australia 7000

A-L Ponsonby

T Dwyer

D Couper

J A Cochrane

Department of Epidemiology and Public Health, Yale University, New Haven, Connecticut, USA

S V Kasl

Correspondence to: Dr Ponsonby.

Accepted 4 November 1994 campaigns to reduce the prevalence prone position have been followed by a decline in SIDS and postneonatal mortality in Tasmania, ${ }^{2}$ Australia, ${ }^{34}$ New Zealand, ${ }^{5}$ the Netherlands, ${ }^{6}$ and the UK. ${ }^{7}$

The Tasmanian cohort study has been used to provide impact ${ }^{8}$ and outcome ${ }^{9}$ evaluation of public health activities to reduce the prevalence of prone sleeping. The rate of SIDS in Tasmania declined from a mean (range) of $3.4(2 \cdot 6-4 \cdot 2)$ cases per 1000 live births in $1988-90$ to $1.6(0 \cdot 9-2 \cdot 3)$ cases during 1991 and $1992 .{ }^{9}$ A within cohort analysis found most of the SIDS rate decline could be attributed to changes in infant sleeping position. ${ }^{9}$ In the cohort, $30 \%$ of infants born between 1 May 1988 and 30 April 1991 slept prone compared with $5 \%$ of infants born from 1 May 1991 to 30 April $1992 .^{8}$ In the later period, there was a high awareness of the association between prone position and SIDS $(90 \%){ }^{8}$ Teenage motherhood, low maternal education, paternal unemployment, unmarried motherhood, non-specialist antenatal care, and not reading books to prepare for a baby were associated with non-awareness. Mothers who were unaware were more likely to have babies who usually slept prone. ${ }^{8}$

Because awareness of the association between prone sleeping and SIDS became a de novo antecedent of prone sleeping position and because the level of awareness differs by parental and infant characteristics, it becomes possible to examine if intervention changed the correlates of prone position. Before health education campaigns to promote the side or supine infant sleeping position, we reported that the prone position was positively correlated with the following characteristics in the cohort: older maternal age, higher family income, higher parental education levels, a non-smoking mother, and infants who were low birth weight, premature, or entirely breast fed. ${ }^{10}$ In contrast, the Plunket National Child Health Survey in New Zealand recently reported that prone sleeping among a 1990-1 birth cohort was significantly associated with sociodemographic factors such as lower maternal education, unmarried motherhood, and lower socioeconomic status. ${ }^{11}$

This study aimed to test the hypotheses that: (1) the prone sleeping position had become more closely associated with predictors of low health education uptake after intervention compared with before intervention and (2) the proportion of prone sleeping infants also exposed to conditions that potentiate the risk of the prone position (swaddling, room heating, illness, and bedding type ${ }^{1213}$ ) did not differ by period of birth.

\section{Methods}

A continuing prospective cohort study was started in 1988 to investigate the aetiology of SIDS in Tasmania. It involves the six major obstetric hospitals in the state and represents approximately $93 \%$ of live births. Infants born in these hospitals are assessed using a scoring system to predict those at higher risk of SIDS. 
Table 1 Association of the usual prone sleeping position with factors associated with low health education ${ }^{\star}$ by period of birth (for dates see text)

\begin{tabular}{|c|c|c|c|c|c|c|c|}
\hline \multirow[b]{2}{*}{$\begin{array}{l}\text { Factor } \\
\text { (reference group) }\end{array}$} & \multicolumn{3}{|c|}{ Before intervention } & \multicolumn{3}{|c|}{ After intervention } & \multirow{2}{*}{$\begin{array}{l}\text { p Value } \dagger \\
\text { (difference in } \\
\text { association by } \\
\text { period of birth) }\end{array}$} \\
\hline & No & $\begin{array}{l}\% \\
\text { Prone }\end{array}$ & OR $(95 \% C I)$ & No & $\begin{array}{l}\% \\
\text { Prone }\end{array}$ & OR $(95 \% C I)$ & \\
\hline Maternal age $<20$ years $\ddagger$ & 697 & $22 \cdot 5$ & $0.63(0.52$ to 0.77$)$ & 261 & $6 \cdot 9$ & $1.42(0.82$ to 2.47$)$ & 0.0069 \\
\hline $\begin{array}{l}\text { (Maternal age } \geqslant 20 \text { years) } \\
\text { Maternal education }<12 \text { years } \neq\end{array}$ & $\begin{array}{l}2969 \\
2900\end{array}$ & $\begin{array}{l}31 \cdot 6 \\
27 \cdot 0\end{array}$ & $0.54(0.45$ to 0.63$)$ & $\begin{array}{l}1009 \\
1057\end{array}$ & $\begin{array}{l}5 \cdot 0 \\
5 \cdot 5\end{array}$ & $16(0.58$ to 2.31$)$ & 0.031 \\
\hline (Maternal education $\geqslant 12$ years) & 760 & 40.9 & 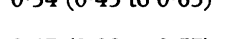 & 210 & $4 \cdot 8$ & $1.10(0.002010)$ & 00519 \\
\hline $\begin{array}{l}\text { Paternal unemployment } \\
\text { (Paternal employment) }\end{array}$ & $\begin{array}{r}755 \\
2802\end{array}$ & $\begin{array}{l}18 \cdot 7 \\
33 \cdot 0\end{array}$ & $0.47(0.38$ to 0.57$)$ & $\begin{array}{l}344 \\
880\end{array}$ & $\begin{array}{l}5 \cdot 8 \\
5 \cdot 1\end{array}$ & $1.15(0.67$ to 1.97$)$ & 0.002 \\
\hline Non-married $\ddagger$ & 1417 & $22 \cdot 3$ & $0.54(0.47$ to 0.63$)$ & 571 & $7 \cdot 2$ & $1.92(1 \cdot 18$ to $3 \cdot 14)$ & 0.0001 \\
\hline Singleton births $\ddagger$ & $\begin{array}{l}2242 \\
3226\end{array}$ & $\begin{array}{l}34 \cdot 7 \\
28 \cdot 8\end{array}$ & $0.66(0.54$ to 0.82$)$ & $\begin{array}{r}698 \\
1100\end{array}$ & $\begin{array}{l}3.9 \\
5.5\end{array}$ & $1.18(0.55$ to 2.5$)$ & $0 \cdot 1536$ \\
\hline (Multiple births) & 444 & $37 \cdot 8$ & & 171 & $4 \cdot 7$ & & \\
\hline $\begin{array}{l}\text { No specialist antenatal care } \\
\text { (Specialist antenatal care) }\end{array}$ & $\begin{array}{l}1523 \\
2140\end{array}$ & $\begin{array}{l}23 \cdot 4 \\
34 \cdot 5\end{array}$ & $0.58(0.50$ to 0.67$)$ & $\begin{array}{l}622 \\
647\end{array}$ & $\begin{array}{l}5 \cdot 8 \\
5 \cdot 0\end{array}$ & $1 \cdot 18(0.72$ to 1.93$)$ & 0.0062 \\
\hline $\begin{array}{l}\text { No books read to prepare for baby } \neq \\
\text { (Books read to prepare for baby) }\end{array}$ & $\begin{array}{l}1870 \\
1794\end{array}$ & $\begin{array}{l}28 \cdot 6 \\
31 \cdot 2\end{array}$ & $0.88(0.77$ to 1.02$)$ & $\begin{array}{l}634 \\
636\end{array}$ & $\begin{array}{l}7 \cdot 3 \\
3 \cdot 5\end{array}$ & $2 \cdot 18(1.31$ to $3 \cdot 64)$ & 0.0010 \\
\hline $\begin{array}{l}\text { Maternal postnatal smoking } \\
\text { (No maternal postnatal smoking) }\end{array}$ & $\begin{array}{l}1717 \\
1938\end{array}$ & $\begin{array}{l}25 \cdot 3 \\
33 \cdot 9\end{array}$ & $0.66(0.57$ to 0.76$)$ & $\begin{array}{l}586 \\
680\end{array}$ & $\begin{array}{l}5 \cdot 0 \\
5 \cdot 7\end{array}$ & $0.86(0.52$ to 1.40$)$ & $0 \cdot 3211$ \\
\hline $\begin{array}{l}\text { Mother smokes in same room as infant } \$ \\
\text { (Mother never smokes in same room as }\end{array}$ & 1390 & 23.5 & $0.60(0.52$ to 0.70$)$ & 440 & $5 \cdot 9$ & $1.17(0.71$ to 1.94$)$ & 0.0132 \\
\hline $\begin{array}{l}\text { infant) } \\
\text { Infant formula fed (full or partial) } \\
\text { (Infant not formula fed (full or partial)) }\end{array}$ & $\begin{array}{l}2265 \\
2415 \\
1253\end{array}$ & $\begin{array}{l}33 \cdot 8 \\
26 \cdot 3 \\
36 \cdot 6\end{array}$ & $0.62(0.54$ to 0.72$)$ & $\begin{array}{l}826 \\
821 \\
450\end{array}$ & $\begin{array}{l}5 \cdot 1 \\
5 \cdot 9 \\
4 \cdot 4\end{array}$ & $1.34(0.78$ to $2 \cdot 28)$ & 0.0065 \\
\hline
\end{tabular}

*All factors but for maternal postnatal smoking and formula feeding have been found to be significantly associated with unawareness of the association between prone sleeping position and SIDS in the cohort.

tAssociated with Wald $\chi^{2}$ statistic for term in logistic model for the interaction between period of birth and the factor in relation to sleeping position. ‡Data collected at hospital interview. §Data collected at home interview.

The development and performance of this model is described elsewhere. ${ }^{14}$ The infants are given a composite score based on low maternal age, low birth weight, season of birth, infant sex, duration of the second stage of labour, and infant feeding. Infants with a score over a certain cut off point are eligible to join the study. Between 1 January 1988 and 30 April $1992,20 \%$ of infants in the cohort were born to teenage mothers, $22 \%$ were of low birth weight, $69 \%$ were boys, $36 \%$ were born in March or April, and $65 \%$ of infants were bottle fed (full or partial) at 1 month of age. All multiple births were included in the study and $12 \%$ of study infants were in this category. Infants with severe neonatal disease or a major congenital anomaly, infants who would not be resident in Tasmania at 1 month of age, and infants for adoption were excluded from the study.

Standard study measurements were collected by research assistants in three stages. Firstly, an interview was conducted when the infant was 4 days old. Sociodemographic, obstetric and perinatal data, including information on maternal nutrition, alcohol and smoking practice during pregnancy, were obtained as well as birth weight, height, head circumference, and triceps and subscapular skinfold thickness measurements. Secondly, a home visit took place during the fifth postnatal week. Premature infants ( $\leqslant 36$ weeks' gestation) were seen at 40 weeks' postconceptional age. The home visit was deferred if the infant had not been discharged from hospital at least two weeks previously. A comprehensive questionnaire was administered. This included the question, 'What position does baby usually sleep in?' Data were also obtained on usual sleep pattern, body movement during sleep, infant illness and health service usage, pattern and type of infant feeding, parental smoking practice, infant overnight clothing and bedding, home heating and housing, and other characteristics of the infant and parental care. Anthropometric and temperature measurements were made on the infant and a developmental assessment conducted. The physical features of the house were noted, and readings were taken for humidity and 24 hour maximum and minimum infant bedroom temperature on the day of home visit. Thirdly, a phone interview was conducted when the infant was 10 weeks of age, to review progress, illness history, feeding, and immunisation.

From 1 January 1988 until 30 April 1992, 6168 live born infants were eligible for inclusion in the survey. This represents approximately one fifth of all live births in the state. A total of $5925(96 \%)$ of these eligible infants and their mothers participated in the hospital interview and $5403(88 \%)$ participated in both the hospital and home interviews.

\section{STATISTICAL METHODS}

Infants born 1 May 1988 to 30 April 1991 and 1 May 1991 to 30 April 1992 were classified into before intervention and after intervention birth cohorts respectively. The period of birth classification used in this report does not reflect a clear demarcation by a single intervention. There were multiple public health activities to reduce the prevalence of prone sleeping. They are discussed elsewhere. ${ }^{8}$ It does, however, delineate a date (1 May 1991) after which cohort participants were informed of the association between sleeping position and SIDS. The proportion of infants sleeping prone was examined by period of birth for infants with the characteristics listed in table 1 . All analyses were done using SAS version 6.07. The univariate odds ratio (OR) and corresponding $95 \%$ confidence interval (CI) for the association between each factor and usual prone position were calculated. Logistic regression models ${ }^{15}$ were then built to assess if the association between a factor and prone position varied by period of birth. Each model 
Table 2 Proportion of prone infants who are also exposed to a possible effect modifier by period of birth (for dates see text)

\begin{tabular}{|c|c|c|c|c|c|c|c|}
\hline \multirow[b]{2}{*}{$\begin{array}{l}\text { Possible effect modifier of } \\
\text { prone position risk }\end{array}$} & \multicolumn{3}{|c|}{ Before intervention } & \multicolumn{3}{|c|}{ After intervention } & \multirow[b]{2}{*}{$\stackrel{p}{\text { Value }}$} \\
\hline & $\begin{array}{l}\text { Total } \\
\text { No } \\
\text { prone }\end{array}$ & $\begin{array}{l}\text { Prone+ } \\
\text { factor }\end{array}$ & $\begin{array}{l}\% \text { Of prone } \\
\text { infants } \\
\text { with factor }\end{array}$ & $\begin{array}{l}\text { Total } \\
\text { No } \\
\text { prone }\end{array}$ & $\begin{array}{l}\text { Pronet } \\
\text { factor }\end{array}$ & $\begin{array}{l}\% \text { Of prone } \\
\text { infants } \\
\text { with factor }\end{array}$ & \\
\hline $\begin{array}{l}\text { Swaddling - infant swaddled or would be swaddled in } \\
\text { cold winter weather } \\
\text { Natural fibre (teatree or kapok) mattress used } \\
\text { Heater observed in infant's bedroom during home visit } \\
\text { Sheepskin use } \\
\text { Positive history of a cold by home visit } \\
\text { Positive history of fever by home visit } \\
\text { Positive history of vomiting by home visit } \\
\text { Positive history of diarrhoea } \\
\text { Thermal insulation hypothetically applied to infant on a }\end{array}$ & $\begin{array}{l}1082 \\
1088 \\
1088 \\
1080 \\
1094 \\
1094 \\
1093 \\
1094\end{array}$ & $\begin{array}{r}536 \\
345 \\
365 \\
398 \\
369 \\
98 \\
217 \\
158\end{array}$ & $\begin{array}{r}49.5 \\
31.7 \\
33.6 \\
36.9 \\
33.7 \\
9.0 \\
19.9 \\
14.4\end{array}$ & $\begin{array}{l}64 \\
68 \\
67 \\
64 \\
68 \\
68 \\
68 \\
68\end{array}$ & $\begin{array}{r}36 \\
19 \\
22 \\
12 \\
23 \\
5 \\
19 \\
11\end{array}$ & $\begin{array}{r}56 \cdot 3 \\
27 \cdot 9 \\
32 \cdot 8 \\
18 \cdot 8 \\
33.8 \\
7.4 \\
27 \cdot 9 \\
16 \cdot 2\end{array}$ & $\begin{array}{l}0.29 \\
0.50 \\
0.89 \\
0.004 \\
0.99 \\
0.63 \\
0.15 \\
0.70\end{array}$ \\
\hline $\begin{array}{l}\text { cold winters night in an unheated room }>6 \text { togs } \\
\text { Infant has experienced a perspiration episode unrelated }\end{array}$ & 1073 & 465 & $43 \cdot 3$ & 62 & 23 & $37 \cdot 1$ & 0.33 \\
\hline to febrile illness & 1096 & 736 & $67 \cdot 2$ & 68 & 42 & $61 \cdot 8$ & 0.37 \\
\hline
\end{tabular}

consisted of a term for the putative factor, period of birth, and an interaction term for the putative factor and period of birth. Postconceptional age at the home visit was also included if data on the study factor had been collected at home visit. The outcome term for all models was a binary term (which was one if the infant usually slept prone at home visit). The effect of period of birth on the association between the factor of interest and prone position was based on the $p$ value associated with the Wald $\chi^{2}$ test for the term in the model. ${ }^{15}$ In a second set of models, marital status and an interaction term for marital status and period of birth were also included to examine the residual effect of period of birth on the association between each factor and prone position after adjustment for the confounding and modification by marital status. The hierarchy principle was observed for all analyses. ${ }^{16}$ The proportion of prone sleeping infants who were exposed to a possible effect modifier was calculated by period of birth (table 2). A test of two proportions ${ }^{17}$ was conducted to assess if the proportion of jointly exposed prone sleeping infants varied by period of birth.

\section{Results}

The association between parental and infant factors and the prone sleeping position by period of birth is shown in table 1 . In the before intervention cohort, respondents who had the following characteristics were significantly $(p<0.05)$ less likely to have an infant who usually slept prone: teenage motherhood, low maternal education, paternal unemployment, unmarried motherhood, singleton birth, non-specialist antenatal care, maternal smoking, poor maternal smoking hygiene, and bottle feeding. In the after intervention cohort, however, respondents with these characteristics were, with the exception of maternal smoking, more likely to have infants who usually slept prone compared with their reference group. However, the differences between the proportion of infants sleeping prone in each group compared with its reference group was larger in the before intervention population than the population after intervention and only two groups unmarried mothers and mothers who did not read books to prepare for a baby - had a significantly $(p<0.05)$ higher proportion of prone sleeping infants compared with their reference groups in the period after intervention.

Logistic regression modelling was used to examine the effect of intervention on the relationship of these variables to sleeping position after adjustment for marital status. Unmarried mothers were less likely $(O R=0.54 ; 95 \%$ CI 0.47 to 0.63 ) to place their infants prone before intervention and more likely $(\mathrm{OR}=1.92 ; 95 \% \mathrm{CI} 1.18$ to 3.14$)$ to place infants prone after intervention compared with married mothers. After adjustment for marital status, it was found that period of birth no longer significantly altered the association between the prone sleeping position and maternal education, maternal age, maternal postnatal smoking or smoking hygiene, or paternal unemployment. The effect of period of birth on the association between bottle feeding or reading books to prepare for a baby and prone sleeping position did, however, remain significant with $p$ values of 0.048 and 0.002 respectively.

The dramatic reduction in the prevalence of the prone position was, as one would expect, accompanied by a reduction in the proportion of infants who were jointly exposed to this position and various conditions which potentiate SIDS risk in the prone position. Therefore, to examine if the distribution of effect modifiers within the prone sleeping sample differed by period of birth, the proportion of prone infants who were also exposed to a possible effect modifier was examined by period of birth. The proportion of prone infants who also slept on sheepskins or would sleep on infant sheepskins in cold winter weather significantly decreased after intervention (table 2). There was no significant change in the proportion of prone infants who were also jointly exposed to the following possible effect modifiers - natural fibre mattresses, swaddling, observed infant room heating device, heavy hypothetical thermal insulation during cold winter weather, perspiration episodes, or a history of illness in terms of fever, upper respiratory tract infection, vomiting, or diarrhoea (table 2).

\section{Discussion}

We examined the correlates of the usual prone position in two birth cohorts, representing infants who were born before and after 
intervention to reduce the prevalence of the prone sleeping position. The period of birth classification used in this report does not reflect a clear demarcation by a single intervention There were multiple public health activities to reduce the prevalence of the prone sleeping position. It does, however, delineate a date (1 May 1991) after which cohort participants were informed of the association between sleeping position and SIDS.

In the before intervention cohort, the prone position was less commonly found among infants born to mothers with characteristics associated with a lower health education uptake (table 1). In the after intervention population, these characteristics had become significantly more closely associated with the prone sleeping position. The proportion of prone infants who were jointly exposed to a possible risk potentiator of the prone position did not vary significantly by period of birth with the exception of the percentage of prone infants with exposure to underlying sheepskin, which was reduced in the latter time period.

The difference in the proportion of infants sleeping prone between subjects with a low health education uptake characteristic and their reference group was less marked after than before intervention. We have previously reported that the most common reason stated for babies usually sleeping prone was that babies slept better or were more comfortable or content in this position. ${ }^{8}$ Thus, it appears that the predictors of choosing the prone position for infants lie in their behaviour, as well as in the sociodemographic characteristics of their parents. The residual group of prone infants after intervention are likely to include those with such behaviour. These results suggest that health education activities, rather than concentrating only on population subgroups such as teenage mothers, should also focus on the use of appropriate methods to settle an infant without resorting to the prone position.

Research findings on possible effect modifiers of the prone position have only recently been published, ${ }^{12} 1318$ so it is not surprising that the proportion of prone infants who were also exposed to a possible effect modifier was not changed by intervention in 1991. Our findings suggest that the component of the recent SIDS rate drop in the cohort $^{2}$ due to a reduction in the joint exposure of prone infants to other possible effect modifiers is small. A substantial proportion of sleeping infants were jointly exposed to a potential risk potentiator of the prone position in the period after intervention. Thus, a further aim of health education in this area should be to inform the minority of parents who are instructed to place their infants prone for medical reasons to avoid risk potentiators such as soft natural fibre mattresses.

This report found that the constellation of confounders of the association between prone position and SIDS changed by period of birth. For example, young maternal age is a risk factor for SIDS. Before intervention, young mothers were less likely to have prone sleeping infants. Thus young maternal age would have acted as a positive confounder in this population, acting to move the unadjusted relative risk toward unity. However, in the cohort after intervention, teenage motherhood was more closely associated with the prone sleeping position. This change would result in moving the unadjusted relative risk for prone position away from unity. Several of the factors listed in table 1 have been shown to increase SIDS risk. It follows that the residual group of prone sleeping infants after intervention are more likely to have other sufficient causes ${ }^{19}$ for SIDS. Thus one would expect the documented change in constellation of confounders to lead to an increase in the unadjusted level of risk, whether relative or absolute, measured for prone infants in the latter time period.

The alteration in correlates of the prone position that we report reinforces the theoretical concept that well known, 'modifiable' risk factors for disease tend to be associated with each other on a population and individual level. This phenomenon is also evident from the recent New Zealand national data, where the significant sociodemographic associations with prone sleeping have all been noted as independent risk factors for SIDS in various studies. ${ }^{11}$

In conclusion, we have documented changes in correlates of the usual prone sleeping position after intervention to reduce the prevalence of the prone sleeping position among cohort infants. It is important to be aware of these changes to understand the risk level of SIDS of prone sleeping infants after intervention and for the planning of SIDS education programmes.

The study was supported by the National Sudden Infant Death Syndrome Council of Australia and constituent organisations, Tasmanian State Government, Australian Rotary Health Research Fund, National Health and Medical Council of Australia, National Institutes of Health, USA, Australian Commonwealth Government, Zonta International, Wyeth Pharmaceuticals, and Tasmanian Sanatoria After-Care Association.

We are indebted to the parents and infants who participated in the cohort study; $K$ Evans, $H$ Donaldson, $M$ Smiley, and in the coht sto other assistants for data collection; to all the.organisations and practitioners involved in SIDS education activities; to the cooperation, and to the hospitals participating in the cohort study.

1 Guntheroth WG, Spiers PS. Sleeping prone and the risk of sudden infant death syndrome. $\mathscr{F A M A}$ 1992; 267: 2359-62.

2 Dwyer T, Ponsonby AL, Newman NM, Gibbons LE. Tasmania: the cohort study and a decline in SIDS rate in 1991 compared to previous years. In: Walker AM, McMillen C, eds. Proceedings of the 2nd SIDS International Conference. New York: Perinatology Press, 1993: 35-43.

Conference. New ecommendations of meeting. A scientific review of the infant death syndrome. $\mathcal{F}$ Paediatr Child Health 1991; 27: infant

4 Australian Bureau of Statistics. Deaths 1988-1992, Australia. Canberra: ABS, 1988-1992. (Catalogue number 3302.0.)

5 Mitchell EA, Ford RPK, Taylor BJ, et al. Further evidence supporting a casual relationship between prone sleeping position and SIDS. $\mathcal{F}$ Paediatr Child Health 1992; 28 (suppl 1): 9-12.

6 Engelberts AC, de Jonge GA. Choice of sleeping position for infants: possible association with cot death. Arch Dis Child 1990; 65: 462-7.

7 Lewis J, Samuels M, Southall D. Is the decline in cot deaths due to child-health reorganisation? Lancet 1993; 341: 51

8 Ponsonby AL, Dwyer T, Kasl SV, Cochrane JA, Newman NM. An assessment of the impact of public health activities to reduce the prevalence of the prone sleeping position during infancy: the Tasmanian cohort study. Prev Med 1994; 23: 402-8. 
9 Dwyer T, Ponsonby AL, Blizzard L, Newman NM, Cochrane JA. The contribution of changes in the prevalence of prone sleeping position to the decline in SIDS in Tasmania. $\mathcal{F} A M A$ (in press)

10 Dwyer G, Ponsonby AL, Newman NM, Gibbons LE. Prospective cohort study of prone sleeping position and sudden infant death syndrome. Lancet 1991; 337: 1244-7.

11 Tuohy PG, Counsell AM, Geddis DC. Sociodemographic factors associated with sleeping position and location. Arch Dis Child 1993; 69: 664-6.

12 Ponsonby AL, Dwyer T, Gibbons LE, Cochrane JA, Wang YG. Factors potentiating the risk of sudden infant death YG. Factors potentiating the risk of sudden infant death Med 1993; 329: 377-82.

13 Taylor BJ. Prone sleeping and bed-sharing in infancy. Why is there an increased risk of unexpected death? Proceedings of the Annual Conference of the Australian Society for Medical Research. Adelaide, 1993.
14 D'Espaignet E, Dwyer T, Newman NM, et al. The development of a model for predicting infants at high risk of SIDS. Paediatr Perinatal Epidemiol 1990; 4: 422-35.

15 Lemeshow S, Hosmer DW. A review of goodness of fit tatistics for use in the development of logistic regression models. Am F Epidemiol 1982; 115: 92-106.

16 Greenland S. Modelling and variable selection in epidemiologic analysis. Am $\mathcal{F}$ Public Health 1989; 79; $340-9$.

17 Fleiss JL. Statistical methods for rates and proportions. 2nd Ed New York: John Wiley and Sons, 1981.

18 Bolton DPG, Taylor BJ, Campbell AJ, Galland BG Cresswell C. Rebreathing expired gases from bedding: a cause of cot death? Arch Dis Child 1993; 69: 187-90.

19 Rothman KJ. Modern epidemiology. Boston: Little, Brown, 1986. 